\title{
Evaluation of Hepatoprotective Potential of Rhododendron arboreum Sm. Stem Bark as Abhava Pratinidhi Dravya (Substitute) of Rohitaka (Tecomella undulata (Sm.) Seem.) Against Paracetamol Induced Hepatotoxicity in Experimental Rats
}

\author{
Puneshwar Keshari*, Pradeep, Sudhakar Bhat
}

Puneshwar Keshari*, Pradeep, Sudhakar Bhat

Department of Dravyaguna, SDM College of Ayurveda and Hospital, Hassan- 573201 Karnataka, INDIA.

\section{Correspondence}

Dr. Puneshwar Keshari

$\mathrm{MD}$ in Dravyaguna

Department of Ayurveda and Alternative

Medicine, Teku, Kathmandu, Nepal

Mobile no: $+977-9844057170$

Fax no. +977-014269912

E-mail: dr.puneshwarkeshari@gmail.com

History

- Submission Date: 12-12-2018;

- Review completed: 02-04-2019;

- Accepted Date: 22-04-2019.

DOI : 10.5530/pj.2019.11.179

Article Available online

http://www.phcogj.com/v11/i5

Copyright

(c) 2019 Phcogj.Com. This is an openaccess article distributed under the terms of the Creative Commons Attribution 4.0 International license.

\begin{abstract}
Background: Rohitaka (Tecomella undulata (Sm.) Seem.) has been considered as threatened and listed as rare at international level (IUCN, 2000). In Ayurveda classics, Rohitaka is described as Yakritpleehgulmodarhara (useful in liver and spleenic disorders). Rhododendron arboreum Sm. is used by folklore practitioners for treatment of Jaundice and marketed as Rohitaka in Nepal. Aim: To evaluate Rhododendron arboreum Sm. as an effective pratinidhi dravya (substitute) in abhava (absence) of Rohitaka (Tecomella undulata (Sm.) Seem.) with special reference to hepatoprotective activity in paracetamol induced hepatotoxicity in rats. Materials and Methods: In the present study, hepatoprotective effect of Choorna (powder) and Kwatha (decoction) of Rhododendron arboreum Sm. and Tecomella undulata (Sm.) Seem. (Choorna- $0.54 \mathrm{~g} / \mathrm{kg}$ body wt. and Kwatha- $4.32 \mathrm{ml} / \mathrm{kg}$ body wt. p. o. for 10 days along with paracetamol toxicant $3 \mathrm{~g} / \mathrm{kg}$ body wt. p. o. on $6^{\text {th }}$ and $8^{\text {th }}$ day) were investigated against paracetamol induced hepatotoxicity. Silymarin $(100 \mathrm{mg} / \mathrm{kg}$ body wt.) was used as standard hepatoprotective reference drug. Statistical Analysis Used: The obtained data were analyzed by ANOVA with Dunnet's multiple ' $t$ ' test and level of $p<0.05$ was considered as statistically significant. Results: Paracetamol treatment led to elevated levels of liver marker enzymes and disorientation in histological observations which were significantly reversed by treatment with Rhododendron arboreum Sm. and Tecomella undulata (Sm.) Seem. dependent on dosage forms. Conclusion: The study revealed that both the drugs have similar hepatoprotective effect and thus Rhododendron arboreum Sm. as "Abhava Pratinidhi Dravya" for Tecomella undulata (Sm.) Seem. with special reference to hepatoprotective activity is justified.
\end{abstract}

Key words: Rohitaka, Abhava Pratinidhi Dravya, Substitute, Hepatoprotective, Choorna, Kwatha, Tecomella undulata, Rhododendron arboreum.

\section{INTRODUCTION}

Liver diseases are one of the most common prevailing problems in the health sector which may be classified as acute or chronic hepatitis, hepatosis (non-inflammatory diseases) and cirrhosis. Liver diseases are mainly caused by toxic chemicals, excess consumption of alcohol, infections and autoimmune disorders. It has been estimated that about $90 \%$ of the acute hepatitis is due to viruses. The major viral agents involved are Hepatitis A, B, C, D, E and G. ${ }^{1}$ The global crude annual incidence rate for Liver disease is 14 per 100000 populations and standardized annual incidence rate is 8.1 per 100000. The recent reports have shown that $10 \%$ of world population is affected with various types of liver diseases. WHO fact sheets on hepatitis has shown that 60,000 persons die of the acute and chronic hepatitis B annually and more than 170 million populations worldwide have affected with long term infection with Hepatitis-C. ${ }^{2}$

There are a number of drugs or therapies available for the treatment of hepatic disorders, but still there is a need for the novel drug discovery because of various adverse reactions and expensiveness. Hence drugs from herbal origin are becoming popular and acceptable worldwide. It has been reported that about 170 phytoconstituents isolated from 110 plants belonging to 55 families do possess hepatoprotective effect. ${ }^{3}$

A number of species have been rendered vulnerable to extinction due to loss of biodiversity and habitat of plant community. Such plants of high medicinal value need to be replaced with the other drugs as substitutes which perform similar pharmacological action. However, the concept of drug substitution in Ayurveda is termed as "Abhava Pratinidhi Dravya". It is said that in the abhava (absence) of a genuine drug, another drug which has similar rasa (taste), guna (properties), veerya (potency), vipaka (metabolites) can be used and known as its pratinidhi dravya. ${ }^{4,5}$

Thus, this is the need of the hour for an appropriate and scientific method of study to illuminate the reasoning behind instigating the concept of Abhava Pratinidhi Dravya in Ayurveda.

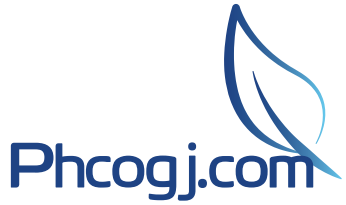

Cite this article: Keshari P, Pradeep, Bhat S. Evaluation of Hepatoprotective Potential of Rhododendron arboreum Sm. Stem Bark as Abhava Pratinidhi Dravya (Substitute) of Rohitaka (Tecomella undulata (Sm.) Seem.) Against Paracetamol Induced Hepatotoxicity in Experimental Rats. Pharmacog J. 2019;11(5):1148-54. 
Rohitaka (Tecomella undulata (Sm.) Seem.) of family Bignoniaceae is described as Yakritpleehgulmodarhara (beneficial in liver and spleenic disorders $)^{6,7}$ and has hepatoprotective action. ${ }^{8}$ The species of Tecomella undulata is restricted to the drier parts of Arabia, southern Pakistan and North - West India ${ }^{9}$ and has been considered as threatened in Rajasthan province of India. It is also include under category I Indeterminate, to stop further exploitation of this species and listed as rare at the international level (IUCN, 2000). ${ }^{10}$

Rhododendron arboreum Sm. of family Ericaceae is the national flower of Nepal and known as Laliguransa or Guransa and is the state tree of Uttarakhanda. It is used by folklore traditional practitioners of Nepal for treatment of Jaundice. Guransa is also mentioned as Rohitaka in Chandra Nighantu; a hand written manuscript in Nepal. Stem bark of Rhododendron arboreum is marketed as Rohitaka in herbal drug trade.

As Tecomella undulata is endangered, it is of at most important to find newer, more easily available and effective substitute. Hence this study has been taken up to evaluate and validate usage of Rhododendron arboreum Sm. as an efficient substitute or Abhava Pratinidhi Dravya for Rohitaka (Tecomella undulata (Sm.) Seem.) with special reference to hepatoprotective activity.

\section{MATERIALS AND METHODS}

\section{Collection of the drug}

The barks of the drug Rohitaka (Tecomella undulata Sm. (Seem.) was collected from its natural habitat of Jaipur, Rajasthan in month of February 2017 and barks of the drug Rhododendron arboreum Sm. was collected from its natural habitat of Pharphing, Kathmandu, Nepal in month of April 2017. Their authentication was confirmed from the Department of Dravyaguna, Shri Dharmasthala Manjunatheshwara College of Ayurveda and Hospital, Hassan. The obtained barks were cut into pieces of variable length and diameter. They were kept for drying approximately for a period of fifteen days under shade.

\section{Preparation of the drug}

The dried barks of both the drugs were then subjected to pounding into coarse powder form with the help of pulverizer at the pharmacy of Shri Dharmasthala Manjunatheshwara College of Ayurveda and Hospital, Udupi. The obtained powder was then sieved through a mesh of sieve number 80 into fine powder. The fine powder was preserved in airtight containers. The Kashaya (decoction) preparation of both drugs were done in pharmacological lab of SDM Centre of Research in Ayurveda and Allied Sciences, Udupi on respective date of administration of drugs into rats according to classical references. ${ }^{11}$

\section{Animals}

Wistar strain albino rats of either sex of body weight ranging from $200-250 \mathrm{~g}$ were selected for the present study. They were obtained from well-established animal house attached to S.D.M Centre for Research in Ayurveda and Allied Sciences, Udupi, Karnataka. They were maintained on feed of "Sai Durga feed and food, Bangalore" and tap water was given ad-libitum. The temperature and humidity were kept at optimum and animals were exposed to natural day night cycles. The experiments were carried out in conformity with the Institutional Animal Ethics Committee (IAEC) and after obtaining its permission (CPCSEA /IAEC/ SDMH-DG-23).

\section{Chemicals}

All the chemicals and reagents used in the experimental study were procured from standard and reputed firms and are of analytical grade regularly used in the laboratory. The biochemical and enzymatic kits for biochemical investigations were obtained from ERBA Diagnostic Mannheim, Transasia Biochemicals Ltd., Daman.

The reference standard drug used for hepatoprotective evaluation is Silymarin. It was purchased from the market with the trade name Silybon -70 mg, Mfg. Lic NO:M/600/2012, Mfd- Oct 2016, Exp- Sep. 2019, B. No. SIAS0004*Manufactured by Micro labs limited, Mamthang, Namthang Road, South Sikkim- 737132

The toxicant used to induce hepatic injury in respective protocol was Paracetamol- Dolo- 650, Mfg. Lic NO: M/600/2012, Mfd- Dec. 2016, Exp- Nov. 2020, B. No. DOBS0612 Manufactured by Micro labs limited, Mamthang, Namthang Road, South Sikkim- 737132, which was procured from local market of Udupi.

\section{Paracetamol induced hepatotoxicity}

Hepatoprotective study using paracetamol induced hepatotoxicity model in rats was carried out using method followed by Sivasubramanian et al. with slight modification. Albino Wistar rats of either sex weighing $200-250$, g were selected and divided into seven groups of six animals in each group $(n=6)$. Treatment was given as described below for 10 days.

\section{Treatment protocol and grouping:}

Group I Vehicle treated: The rats were given normal tap water and Standard laboratory diet.

Group II Paracetamol treated: The rats were given with Paracetamol $3 \mathrm{~g} / \mathrm{kg}$ body weight of rats, one dose on 6 th day and second dose on 8 th day along with normal diet and water.

Group III Standard drug treated: animals received Silymarin $(100 \mathrm{mg} /$ $\mathrm{kg}$, p.o.) in addition to paracetamol.

Group- IV Test drug 1: animals received Choorna (powder) of Tecomella undulata - $(0.54 \mathrm{mg} / \mathrm{g}$ of body wt of rat p.o.) in addition to paracetamol.

Group- V Test drug 2: animals received Kashaya (decoction) of Tecomella undulata $(0.00432 \mathrm{ml} / \mathrm{g}$ of body wt of rat p.o.) in addition to paracetamol.

Group- VI Test drug 3: animals received Choorna (powder) of Rhododendron arboreum- $(0.54 \mathrm{mg} / \mathrm{g}$, p.o.) in addition to paracetamol.

Group- VII Test drug 4: animals received Kashaya (decoction) of Rhododendron arboreum - (0.00432 $\mathrm{ml} / \mathrm{g}$ of body wt of rat p.o.)

The test drugs: Choorna and Kashaya of Tecomella undulata and Rhododendron arboreum and reference drug were administered orally for 10 consecutive days and two doses of the toxicant (Paracetamol) were administered orally to each group, except the normal control group, on day $6^{\text {th }}$ and $8^{\text {th }}$ day, $1 \mathrm{hr}$ after test drug administration. After $48 \mathrm{~h}$ of second dose of toxicant paracetamol, the blood was drawn by puncturing of retro-orbital plexus of each rat of all groups under diethyl ether anesthesia and blood was collected in EDTA containing test tubes and sent for biochemistry laboratory for biochemical investigations. All the rats were sacrificed and important organs like liver, kidney and heart were dissected out, cleaned to remove extraneous tissues, blotted to remove blood stain and weighed. The liver of each rat was preserved in $10 \%$ formalin for histopathological processing.

Serum was separated and serum level of biochemical parameters namely SGOT, SGPT, Total bilirubin, direct bilirubin etc. were estimated as per standard procedure prescribed by manufacturer (AGAPPE diagnostics Ltd., Kerala, India)whereas serum level of ALP was estimated as per standard procedure described by manufacturer (Span diagnostics Ltd., Surat, India) of diagnostic kit. 
Parameters employed for assessing the extent of liver Injury

\section{Ponderal changes}

Organ weight - Liver. The organ weight was presented in terms of relative weight.

\section{Serum biochemical parameters}

The blood was collected and sent to biochemistry laboratory for biochemical investigations involving serum parameters. Serum biochemical parameters were estimated with the help of clinical autoanalyzer (Erba Magnum EM200) by feeding serum sample to the concerned port as per the directions of the manufacturer. The following biochemical parameters were estimated according to standard laboratory procedure; serum glutamic oxaloacetic transaminase (SGOT) activity, serum glutamic pyruvate transaminase (SGPT) activity, Alkaline phosphatase (ALP) activity, Total protein, Albumin, Globulin, Glucose, Total bilirubin and direct bilirubin creatinine, Urea, Cholesterol, Triglycerides.

\section{Histopathological study}

The liver of each rat from each group was collected by dissection of individual rat after sacrificing them by administration of high dose of diethyl ether followed by cervical disc prolapsed. The collected specimen of liver was weighed after cleaning in normal saline and kept in $10 \%$ formaldehyde solution and sent to standard laboratory for histopathological study.

\section{Statistical analysis}

The data obtained were analyzed by using analysis of variance (ANOVA) followed by Dunnett's ' $t$ ' test for determining the level of significance of the observed effects. A 'P' value of less than 0.05 was considered statistically significant.

\section{RESULT AND DISCUSSION}

There are several models available for screening of potential hepatoprotective drugs. The method chosen here is paracetamol induced liver toxicity model to assess the hepatoprotective potential of Tecomella undulata (Choorna and Kwatha) and Rhododendron arboreum (Choorna and Kwatha). Paracetamol, although, a safe drug at therapeutic dose, it may likely to produce fatal reactions and cause death in human and experimental animals in overdose. Paracetamol is metabolised by a cytochrome P-450 dependant pathway to an electrophile metabolite (intermediate reactive) $\mathrm{N}$-acetyl-pbenzoquinoneimine (NAPQI). Therapeutic dose of this drug are safely biotransformed and eliminated as non toxic conjugates of sulphate and glucuoronic acid and only a small fraction is converted to NAPQI, which is detoxified by glutathione (GSH) and eventually eliminated in the urine/bile. During overdose of paracetamol, the glucuronidation and sulfation routes become saturated and more extensive metabolism (of paracetamol), leads to rapid depletion of hepatic GSH levels. Unconjugated NAPQI can exert its cytotoxic effect by covalent binding to cellular macromolecules, membrane lipid peroxidation and alteration of calcium homeostasis. More recently, the cytochrome 2EI, IA2, 3A4 and 4A6 have been reported to oxidize paracetamol to the reactive metabolite resulting in excess release of free radicals ultimately ending in tissue damage. ${ }^{12}$

Paracetamol which is used as an agent to produce hepatotoxicity, has produced substantial hepatotoxicity by resulting in significant fall in the levels of total serum proteins and albumin globulin ratio and a significant increase in ALP, AST and ALT. Increased levels of ALT, AST and ALP in serum of the albino rats indicate liver damage as these enzymes leak out from liver in to the blood at the instance of tissue damage which is always associated with hepatonecrosis. ${ }^{13,14}$

Assessment of liver cell necrosis is most frequently done by estimation of SGOT and SGPT activity. Serum levels of SGOT and SGPT are increased on damage to the tissues producing them. In the present, study also similar elevation was observed. Thus, the observed elevation in transaminase activity can be considered indicative of liver inflammation and injury due to the toxic effect of paracetamol. Transaminase estimations are useful in the early diagnosis of viral hepatitis. Very high levels are seen in extensive acute hepatic necrosis such as in severe viral hepatitis and acute cholestasis. Alcoholic liver disease and cirrhosis are associated with mild to moderate elevation of transaminases.

Effect of test drugs Tecomella undulata Sm. (Seem) and Rhododendron arboreum Sm. on percentage change in body weight

The data shows (Table 1) there was remarkable decrease in percentage change in body weight in paracetamol control group when compared to the normal control and the observed changes were statistically very significant which was reversed by all test drugs and standard reference drug. T2 showed significant increase in percentage change in body weight.

Due to short duration of the study there were no remarkable changes in the body weight pattern hence it is not considered important for assessment of the hepatoprotective potential of the test drug.

\section{Effect of test drugs Tecomella undulata Sm. (Seem) and Rhododendron arboreum Sm. on liver weight}

Standard drug and Test formulation T1, showed decrease in liver weight in comparison to paracetamol control group, however the observed changes were statistically non-significant. Decrease in liver weight was significantly by T4. Non-significant increase was noted by $\mathrm{T} 2$ and T3 drugs. Changes in liver weight of different groups shows (Figure 1) there was not significant differences in T1, T2 and T3 group but in T4 group significant decrease in liver weight was observed.

Table 1: Effect of test drugs (Tecomella undulata and Rhododendron arboreum) on body weight.

\begin{tabular}{ccc}
\hline Group & \multicolumn{2}{c}{ Percentage change in body weight $(\mathbf{g})$} \\
\cline { 2 - 3 } & MEAN \pm SEM & \% Change \\
\hline Normal control & $6.20 \pm 0.93$ \\
Paracetamol control & $-6.75 \pm 3.60^{* *}$ & $208.87 \downarrow @$ \\
Standard & $-1.33 \pm 2.71$ & $80.29 \uparrow \#$ \\
Test 1 (T. undulata Choorna) & $-2.20 \pm 1.36$ & $67.40 \uparrow \#$ \\
Test 2 (T. undulata Kwatha) & $1.54 \pm 1.77^{*}$ & $122.81 \uparrow \#$ \\
Test 3 (R.arboreum Choorna) & $-1.40 \pm 1.35$ & $79.25 \uparrow \#$ \\
Test 4 (R.arboreum Kwatha) & $-1.18 \pm 1.35$ & $82.51 \uparrow \#$ \\
\hline
\end{tabular}

Data: $\mathrm{MEAN} \pm \mathrm{SEM},{ }^{\star} P<0.05,{ }^{* *} P<0.01 @$ - compared with normal control, \#- compared with paracetamol control. 


\section{LIVER (g) MEAN}

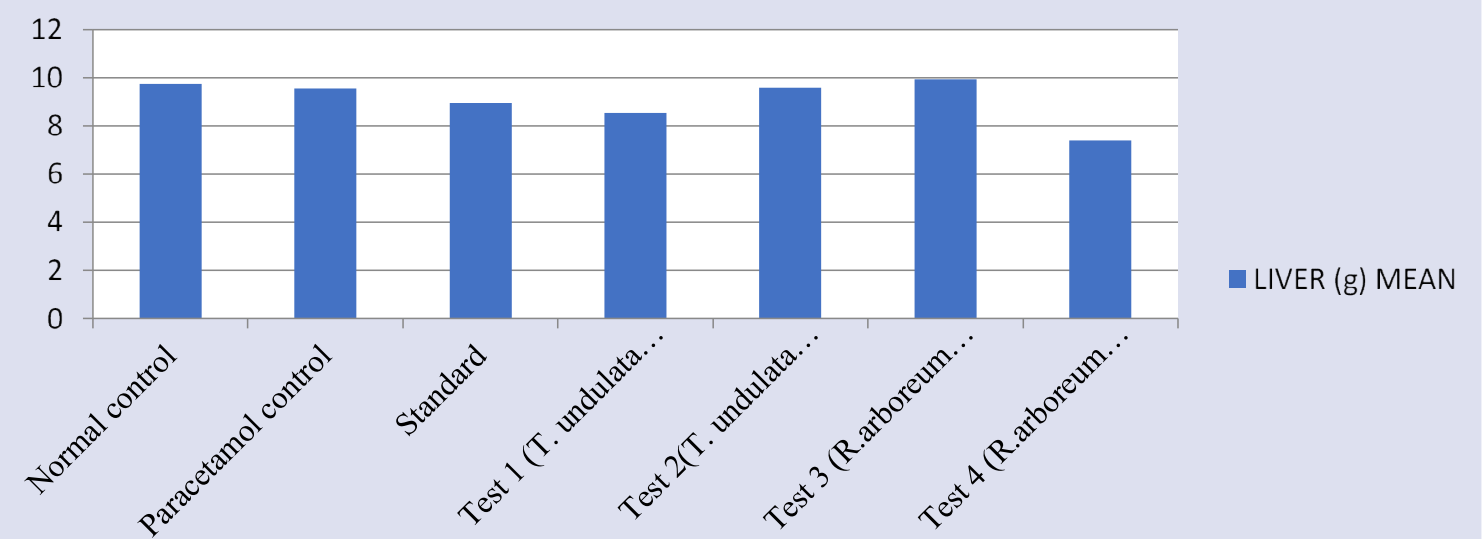

Figure 1: Graphic presentation of liver weight in different groups.

Previous studies showed that paracetamol intoxication may cause centrolubular necrosis in liver. In this parameter, administration of paracetamol leaded to non-significant decrease in weight. This decrease was mildly reversed by T2 and T3 groups used but T4 group showed mild decrease even than paracetamol control group. The decrease may be indicative of liver induction and may not reflect drug induced toxicity.

\section{Effect of test drugs Tecomella undulata Sm. (Seem)} and Rhododendron arboreum Sm. on liver biochemical

\section{parameters}

Among all biochemical parameters in serum, significant increase was observed in SGOT, SGPT, total bilirubin, direct bilirubin indicating hepatotoxicity in paracetamol control group. Thus, elevation in the above parameters can be considered as an index of paracetamol induced hepatic injury and its reversal as sign of expression of hepatoprotection. Significant reversal in the elevation of parameters like SGOT, SGPT, direct bilirubin, and serum cholesterol were observed in T1, while in T2 group significant reversals were seen in SGPT. Direct bilirubin level was significantly decreased in test drug T2 group. Test drug T4 showed significant reversal in elevation of SGOT, SGPT, and serum cholesterol (Tables 2a-2c).

As it is already established, in present study SGOT, SGPT, ALP, Total Bilirubin and direct bilirubin activities were also elevated after administration of paracetamol and observed statistically significant level. The elevated level of SGOT was reversed by all four test drugs in therapeutic doses and reference standard administration. There were significant decrease observed in standard drug and T1 and T4 test drugs groups. SGPT was significantly decreased by the administration of reference standard group and test drugs T1, T2 and T4 at therapeutic doses. There was moderate decrease in alkaline phosphatase activity observed after paracetamol administration. This decrease was mild to moderately reverse by the standard reference drug and test groups $\mathrm{T} 1$, $\mathrm{T} 2$, and $\mathrm{T} 3$ but there was mild decrease in ALP was shown in T4 group of test drug.

This can be considered as indicative of significant hepatoprotection of reference standard and Tecomella undulata Choorna and Kashaya and Kashaya of Rhododendron arboreum however moderate protection in the remaining when considered.

In the present study total bilirubin and direct bilirubin were markedly elevated in paracetamol control group indicating hepatocellular damage. Elevation of total bilirubin was significantly decreased by standard reference drug and mild decrease was observed in test drug groups while direct bilirubin was reversed by both standard reference drug and test drugs T1, T2, T3 and T4. In standard reference group and T3 group there was markedly decrease in direct bilirubin and moderate decrease was seen in T1 group; however mild decrease was observed in $\mathrm{T} 2$ and T4 group. This may be indicative of hepatoprotective activity in test drugs groups.

In previous studies different extracts of Tecomella undulata were established as hepatoprotective. As per study done, it is observed that supplementation of $T$. undulata extract restored the depleted SOD, CAT, GSH and GPx contents near normalcy and also brought down to elevated levels of AST, ALT ALP, GGT (gamma-glutamyl transferase) and total bilirubin. These biochemical restorations are mainly due to the inhibitory effects on cytochrome P450 and/ or glucuronidation. ${ }^{14,15}$ So in this study also we can correlate that test drugs showed hepatoprotective effect due to the same process.

Previous study about Rhododendron arboreum has revealed its bark contains betunilic acid which is potential hepatoprotective. ${ }^{16}$ A study has shown that leaves of Rhododendron arboreum contain alkaloids, tannins, flavonoids, saponins which might be responsible for antioxidant properties and hepatoprotective activity. ${ }^{17}$ In this study the bark of Rhododendron arboreum also showed the presence of those phytochemicals responsible for hepatoprotective activity.

Total serum Protein values decrease below normal range in different clinical conditions associated with nephrotic syndrome, malnutrition, cirrhosis of liver and in other liver diseases in which liver cells are severely damaged. Increased total protein value may be found in multiple myeloma and conditions associated with high globulin concentration. ${ }^{18}$

In the present study serum total protein non significant increase was observed in paracetamol control. Test drugs and standard reference drug mildly decreased total protein which is not significant. Hence its estimation did not contribute to the determination of the hepatoprotective potential of the test formulations and reference standard. Estimation of total serum cholesterol, triglyceride and lipoprotein fraction are frequently done in liver disease. The rise in total serum cholesterol in cholestasis is probably due to retention of cholesterol which is normally excreted in the bile. Serum triglyceride is also elevated in cholestasis. These values are lowered in acute and chronic diffuse liver disease and in malnutrition. ${ }^{19}$

In present study, moderate elevation in serum total cholesterol was observed after paracetamol intoxication which was significantly 
Table 2a: Effect of test drugs Tecomella undulata Sm. (Seem) and Rhododendron arboreum Sm. on liver biochemical parameters.

\begin{tabular}{cccccc}
\hline Groups & SGOT (IU/L) & SGPT (IU/L) & ALP (IU/L) & TBL $(\mathrm{mg} / \mathrm{dl})$ & DBL $(\mathrm{mg} / \mathrm{dl})$ \\
\hline Normal control & $177.66 \pm 26.25$ & $125.33 \pm 12.70$ & $1542.83 \pm 1 \mathrm{O} 3.24$ & $0.20 \pm 0.02$ & $0.078 \pm 0.009$ \\
Paracetamol control & $263.00 \pm 31.89^{*}$ & $247.71 \pm 28.23^{* *}$ & $602.50 \pm 42.06^{* *}$ & $0.36 \pm 0.02^{*}$ & $0.25 \pm 0.01^{* *}$ \\
Standard (Silymarin) & $165.28 \pm 6.89^{* *}$ & $104.85 \pm 13.01^{* *}$ & $1046.33 \pm 268.07$ & $0.20 \pm 0.01^{*}$ & $0.08 \pm 0.01^{* *}$ \\
Test 1 (T. undulata Choorna) & $146.00 \pm 12.86^{* *}$ & $127.40 \pm 15.01^{* *}$ & $711.20 \pm 139.97$ & $0.32 \pm 0.03$ & $0.126 \pm 0.031^{*}$ \\
Test 2 (T. undulata Kwatha) & $190.00 \pm 20.49$ & $153.50 \pm 31.80^{*}$ & $1212.33 \pm 240.87$ & $0.35 \pm 0.02$ & $0.246 \pm 0.018$ \\
Test 3 (R. arboreum Choorna) & $205.6 \pm 24.57$ & $172.60 \pm 20.99$ & $944.60 \pm 160.42$ & $0.31 \pm 0.09$ & $0.068 \pm 0.0139^{* *}$ \\
Test 4 (R. arboreum Kwatha) & $158.33 \pm 10.00^{* *}$ & $76.33 \pm 4.28^{* *}$ & $578.00 \pm 40.57$ & $0.30 \pm 0.04$ & $0.191 \pm 0.0572$ \\
\hline
\end{tabular}

Data: $\mathrm{MEAN} \pm \mathrm{SEM},{ }^{*} P<0.05, * *<<0.01$, @- compared with normal control, \#- compared with paracetamol control.

Table 2b: Effect of test drugs Tecomella undulata Sm. (Seem) and Rhododendron arboreum Sm. on liver biochemical parameters.

\begin{tabular}{|c|c|c|c|c|}
\hline Groups & Sugar(mg/dl) & Albumin (g/dl) & Globulin (g/dl) & Urea(mg/dl) \\
\hline Normal control & $158.00 \pm 4.23$ & $3.30 \pm 0.07$ & $3.25 \pm 0.07$ & $34.66 \pm 1.30$ \\
\hline Paracetamol control & $138.12 \pm 11.75$ & $3.42 \pm 0.08$ & $4.07 \pm 0.14$ & $39.62 \pm 3.39$ \\
\hline Standard (Silymarin) & $104.50 \pm 7.22$ & $3.12 \pm 0.12$ & $3.77 \pm 0.20$ & $26.10 \pm 0.67^{\star *}$ \\
\hline Test 1 (T. undulata Choorna) & $104.00 \pm 16.30$ & $3.18 \pm 0.08$ & $3.56 \pm 18$ & $27.60 \pm 1.56^{* *}$ \\
\hline Test 2 (T. undulata Kwatha) & $112.83 \pm 8.69$ & $3.03 \pm 0.06$ & $3.71 \pm 0.42$ & $28.33 \pm 1.20^{* *}$ \\
\hline Test 3 (R. arboreum Choorna) & $140.20 \pm 4.88^{*}$ & $3.02 \pm 0.13$ & $3.84 \pm 0.24$ & $24.80 \pm 2.81^{\star *}$ \\
\hline Test 4 (R. arboreum Kwatha) & $103.50 \pm 13.21$ & $3.30 \pm 0.20$ & $3.83 \pm 0.22$ & $21.33 \pm 2.34^{\star *}$ \\
\hline
\end{tabular}

Data: MEAN $\pm \mathrm{SEM},{ }^{*} P<0.05,{ }^{* *} P<0.01$, @- compared with normal control, \#- compared with paracetamol control.

Table 2c: Effect of test drugs Tecomella undulata Sm. (Seem) and Rhododendron arboreum Sm. on liver biochemical parameters.

\begin{tabular}{cccc}
\hline Groups & Creatinine(mg/dl) & Cholesterol(mg/dl) & Triglyceride(mg/dl) \\
\hline Normal control & $0.50 \pm 0.07$ & $85.00 \pm 6.27$ & $80.16 \pm 10.13$ \\
Paracetamol control & $0.81 \pm 0.06^{*}$ & $112.50 \pm 12.95$ & $119.00 \pm 12.60$ \\
Standard (Silymarin) & $0.72 \pm 0.05$ & $61.50 \pm 9.34^{* *}$ & $72.50 \pm 5.36$ \\
Test 1 (T. undulata Choorna) & $0.80 \pm 0.07$ & $63.80 \pm 8.05^{* *}$ & $70.40 \pm 8.68$ \\
Test 2 (T. undulata Kwatha) & $0.35 \pm 0.05^{* *}$ & $83.00 \pm 13.16$ & $97.33 \pm 12.12$ \\
Test 3 (R. arboreum Choorna) & $0.74 \pm 0.20$ & $84.60 \pm 5.62$ & $128.60 \pm 11.83$ \\
Test 4 (R. arboreum Kwatha) & $0.38 \pm 0.03^{* *}$ & $61.33 \pm 9.55^{* *}$ & $108.83 \pm 19.88$ \\
\hline
\end{tabular}

Data: MEAN $\pm \mathrm{SEM},{ }^{\star} P<0.05,{ }^{\star *} P<0.01$, @- compared with normal control, \#- compared with paracetamol control.

reversed in reference standard drug, $\mathrm{T} 1$ and $\mathrm{T} 4$ test drug groups. However, the reversion was mild in case of test drugs $\mathrm{T} 2$ and $\mathrm{T} 3$ groups.

Triglyceride level was non-significantly increased in paracetamol intoxication which was mild to moderately reverse by standard reference and test drugs.

Thus, the analysis of serum biochemical parameters shows that administration of Paracetamol leads to significant change in majority of the parameters and there were mild to moderate reversal in biochemical parameters indicating hepatoprotection of test drugs.

\section{Histopathological observations}

Main histopathological changes observed were fatty changes, apoptic changes, Cell depletion, Periportal and pericentral cell infiltration, central vein dilatation, areas of infarct, necrosis, cell infiltration, hyaline changes, extensive hemorrhagic streaks, proliferation of ductal epithelium in paracetamol treated group. These changes ranged from severe to moderate in intensity which was reversed by standard and test drugs. In silymarin (standard) treated group, and test groups T1, $\mathrm{T} 2$ and T4 mild degenerative changes were observed comparable to normal, while in case of test drug T3 moderate degenerative changes were observed (Figure 2)

On the basis of evaluation of biochemical parameters, test drugs showed mild to good hepatoprotection which is also justified by the histopathological findings which has shown less degenerative changes in liver in test drugs treated group with comparison to paracetamol control group and substantiated their hepatoprotective activities. Among all test groups, T1 and T4 groups showed better result while test drugs T2 also showed moderate to good hepatoprotection but hepatoprotection of test drug T3 was not so as required parameters.

Test drug T1 (Choorna of Tecomella undulata (Seem.) Sm.) and Test drug T4 (Kashaya of Rhododendron arboreum Sm.) showed significant hepatoprotection that helps to substantiate the hepatoprotective effect of test drugs are dependent to dosage form. The significant hepatoprotective effect of Rhododendron arboreum $\mathrm{Sm}$. also proved the use of stem bark of Rhododendron arboreum Sm. as a substitute for Rohitaka (Tecomella undulata (Seem.) Sm.). So here the rationale behind substantiating Rhododendron arboreum Sm. as Abhava Pratinidhi Dravya (substitute) of Rohitaka (Tecomella undulata (Seem.) Sm.) is the Karma(action) of the drug.

\section{CONCLUSION}

Analysis of the biochemical parameters and histopathological study data generated during the study clearly indicates the injurious effects produced by toxicant paracetamol were reversed by all test groups as well as reference standard, and test drugs indicating presence of good hepatoprotective effect. Rhododendron arboreum and Tecomella undulata both drugs showed presence of moderate to good hepatoprotection by reversal of important parameters like SGPT, SGOT, Total bilirubin and Direct bilirubin. Hepatoprotective activity showed by test drugs was dependent upon dosage forms. Hence this study is justified. 


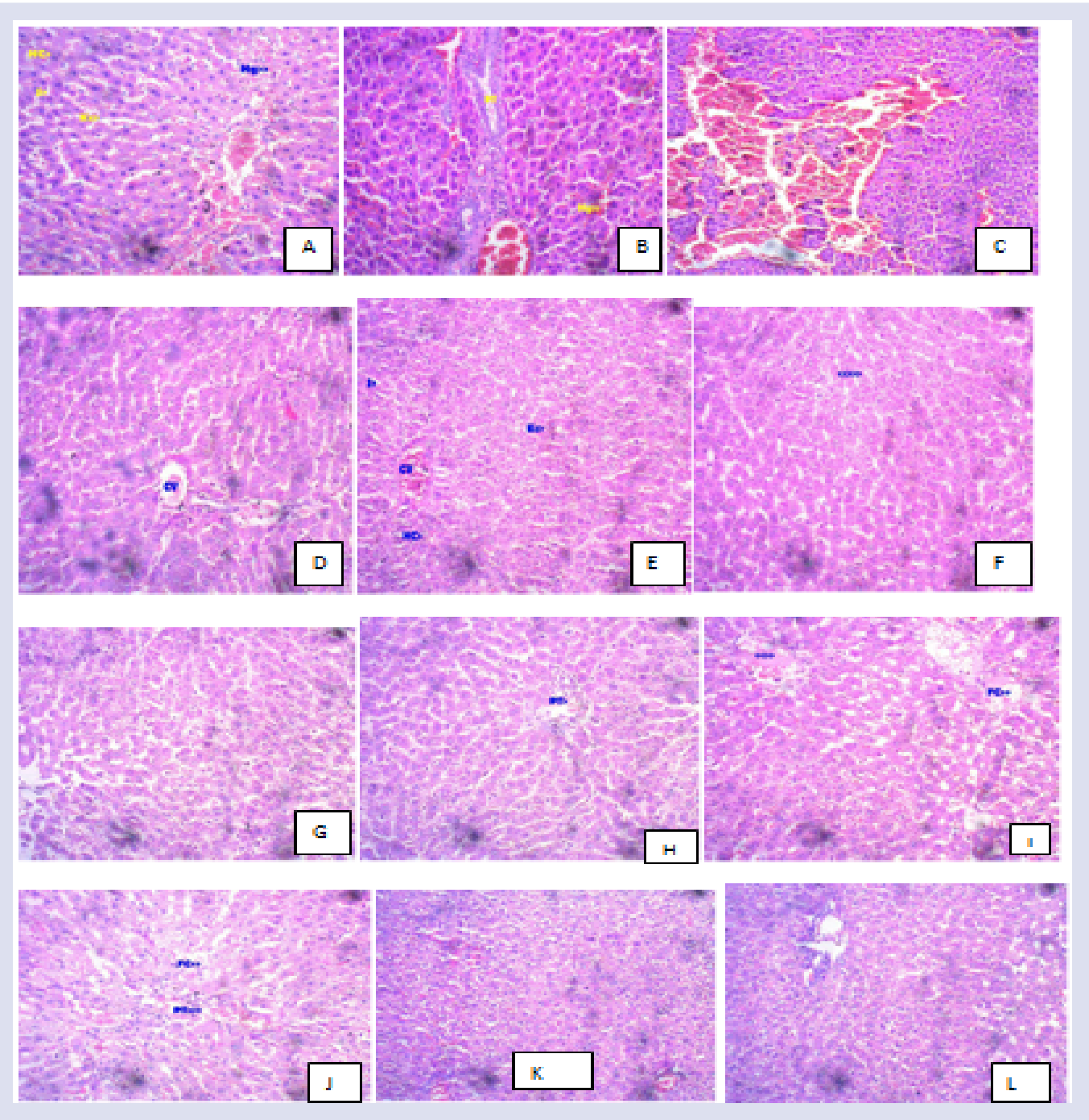

Figure 2: [Paracetamole control(A- extendive hemorrhage $(\mathrm{Hg}), \mathrm{B}$ - hemorrhagic streaks and proliferation of ductal epithelium. C- extensive degenerative changes)], D-normal cytoarchitecture in silymarin group, E7F- Normal cytoarchitecture and mild fatty changes in T1 group, G\&H-Normal structure and mild degenerative changes in T2 group, I \& J-fatty changes (FC) and necrotic changes ( $(<\geq \geq)$ and cell depletion and fatty changes (FC) in T3 group, K \& L- Normal cytoarchitect and mild cell depletion in T4 group.

\section{ACKNOWLEDGEMENT}

Authors are thankful to the Principal, Dr. Prasanna N. Rao and faculty members of Department of Dravyaguna, SDM college of Ayurveda \& Hospital, Hassan for their necessary support and also thankful to Director and all staffs of department of pharmacology, SDM Centre for research in Ayurveda and Allied sciences, Kuthpady, Udupi for providing necessary support and facilities to carry out the study.

\section{CONFLICTS OF INTEREST}

None.

\section{ABBREVIATIONS}

IUCN: International Union of Conservation of Nature; CPCSEA: Committee for the Purpose of Control And Supervision of Experiments on Animals; Mfd: Manufactured Date; Exp: Expire Date; p.o: per orally; EDTA: Ethylene diamine tetra acetic acid; SGOT: Serum Glutamic Oxaloacetic Transaminase; SGPT: Serum Glutamic Pyruvate Transaminase; ALP: Alkaline Phosphatase; ANOVA: Analysis of Variance; NAPQI: N-acetyl-p-benzoquinoneimine; GSH: Glutathione;
AST: Aspartate Aminotransferase; ALT: Alanine Aminotransferase; GGT: Gamma-Glutamyl Transferase; TBL: Total Bilirubin; DBL: Direct Bilirubin; TP: Total Protein.

\section{REFERENCES}

1. Hari KC, Ramesh A, Suresh KJN, Mohammed IB. A review on hepatoprotective activity of medicinal plants. IJPSR. 2011;2(3):501-15.

2. Edward CRW, Bouchier IAD, Haslett C, Chilvers E. Davidson's principles and practice of medicine (seventh edition). NewYork: ELBS with Churchill Liivingstone; 1995:483-4.

3. Handa SS. Plants as drugs. The Eastern Pharmacist. 1991;34:79-85.

4. Shastri VL. Shastri BB. Yogaratnakara. Varanasi: Chaukhambha Prakashan 2012;175.

5. Shastri A, Shastri R. Bhaishajya Ratnavali. 2nd ed.Varanasi: Chaukhambha Sanskrit Samsthan. 39-40.

6. Dhanwantari, Dhanwantari Nighantu, Amradi varga, shloka 119-120, Jharkhande Ojha editor. 2nd edition. Varanasi: Chaukhamba Surbharati; 1996:232.

7. Shodhal Vaidyacharya, Shodhal Nighantu, Guna sngraha, Amradi varga, shloka 522, P.V.Sharma Prof.editor. Varanasi: Chaukamba Orientalia; 1978:136. 
8. Billore KV. Database on medicinal plants used in Ayurveda, vol.6, New Delhi: Central council for research in Ayurveda and Siddha; 2007:321-4.

9. Google search-Tecomella undulata - Wikipedia, the free encyclopedia [cited 2017 December 20]; Available from: http://en.m.wikipedia.org > wiki > Tecoma...

10. Richa D, Shekhawat GS. Critical review on Tecomella undulata: A medicinally potent endangered plant species of Indian Thar desert. International Journal of Current Research. 2012;4(6):036-044.

11. Sharangadharacharya"s "The Sharangadhara Samhita", with Adhamalla"s,"Dipika"e and Kasirama"s "Gudartha Dipika" commentaries, Varanasi,Krishnadas Academy, Reprint 2000,

12. Roy SD, Das S, Shil D, Dutta KN. Herbal hepatoprotective agents: A review. World Journal Pharmaceutical Research;1(2):87-99.

13. Ahmad F, Tabassum N. Experimental models used for the study of antihepatotoxic agents. Journal of Acute Disease. 2012;85-9.
14. Singh D, Gupta RS. Hepatoprotective activity of methanol extract of Tecomella undulata against alcohol and paracetamol induced hepatotoxicity in rats. Life Sciences and Medicine Research. 2011:LSMR-26.

15. Jain M, Kapadia R, Jadeja RN, Thounaojam MC, Devkar RV, Mishra SH. Hepatoprotective potential of Tecomella undulata stem bark is partially due to the presence of betulinic acid. J Ethnopharmacol. 2012;143(1):194-200.

16. Srivastava P. Rhododendron arboreum: An overview. Journal of Applied Pharmaceutical Science. 2012;02(01):158-62.

17. Prakash T, Fadadu SD, Sharma UR, Surendra V, Goli D, Stamina P, Kotresha D. Hepatoprotective activity of leaves of Rhododendron arboreum in $\mathrm{CCl} 4$ induced hepatotoxicity in rats. Journal of Medicinal Plants Research. 2008;2(11):315-20.

18. Harsh Mohan. Text book of pathology. 6th Ed. New Delhi: Jaypee brothers medical publishers (P) LTD; 2010;595-7.

19. Godkar PB, Godkar DP. Text book of medical laboratory technology. 2ndEd. Mumbai: Bhalani publishing house; 2003;235.

\section{GRAPHICAL ABSTRACT}
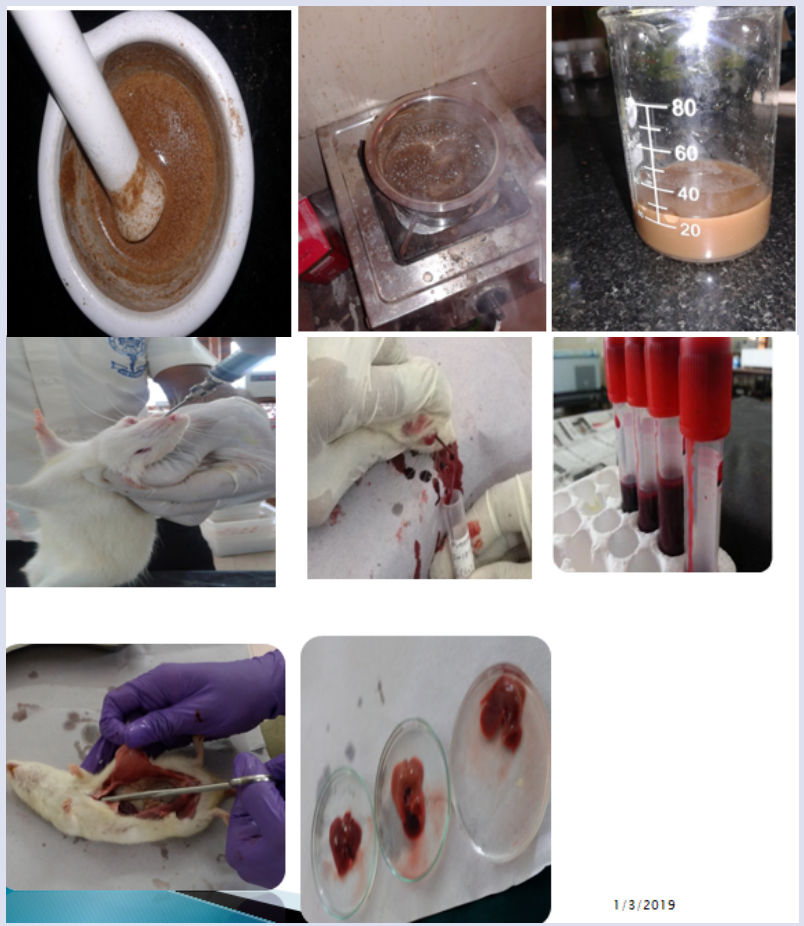

\section{SUMMARY}

The aim of the study was to evaluate the hepatoprotective potential of stem bark of Rhododendron arboreum as a substitute of Tecomella undulata. For this reason, we used 42 Wistar albino rats of both sex, at the experimental model of paracetamol induced hepatotoxicity. We used seven experimental groups (one for normal control, one paracetamol control, one for Standard drug Silymarin, two for stem bark of Tecomella undulata (one choorna and other kwatha) and two for Stem bark of Rhododendron arboreum (one choorna and other kwatha). The result was that the Choorna (powder) of stem bark of Tecomella undulata and Kwatha (aqueous decoction) of stem bark of Rhododendron arboreum have significant hepatoprotective activity, so use of Rhododendron arboreum Sm. stem bark as abhava pratinidhi dravya (substitute) of Rohitaka (Tecomella undulata (Sm.) Seem.) for hepatoprotective activity is established.

\section{ABOUT AUTHORS}

- Dr. Puneshwar Keshari, MD in Dravyaguna (Ayurvedic Pharmacology) from Department of Ayurveda and Alternative Medicine, Teku, Kathmandu, Nepal.

- Dr. Pradeep, MD in Dravyaguna, Associate Professor, Department of Dravyaguna, SDM College of Ayurveda and Hospital, Hassan, India.

- Bhat Sudhakar, Research Officer, SDM Centre For Research In Ayurveda and Allied Sciences, Kuthpady, Udupi, India.

Cite this article: Keshari P, Pradeep, Bhat S. Evaluation of Hepatoprotective Potential of Rhododendron arboreum Sm. Stem Bark as Abhava Pratinidhi Dravya (Substitute) of Rohitaka (Tecomella undulata (Sm.) Seem.) Against Paracetamol Induced Hepatotoxicity in Experimental Rats. Pharmacog J. 2019;11(5):1148-54. 